\title{
Genes and the conceptualisation of language knowledge
}

\author{
ALISON WRAY ${ }^{1}$
}

\begin{abstract}
While it would be difficult to dispute that individuals vary in their facility with both their native language and with foreign languages, a central tenet of modern linguistics has been that such variation is secondary, and there is a primary level of equality across all individuals. Syntactic theory and sociolinguistic theory have both contributed to the maintenance of this view, and it provides a socially acceptable approach to studying language form and function. However, genes are the authors of both similarity and difference, making their role in language complicated to unpick. The proposed syntactic basis for equality has been a genetically-determined 'language faculty', which presumably arose early in the modern species and has reliably persisted in all individuals until today. How much fundamental uniformity of language knowledge is there, though? Does it matter if a key feature is not observed in unwritten languages, if there are languages that permit structures that should be prohibited, or if some individuals are less adept at managing purportedly universally understood configurations than others? How might culturally augmented features in language structure be inappropriately influencing claims about what all languages are like? These questions are directly relevant to those engaging with genetics because of the growing opportunities to explore the relative roles of environment and genes in determining aspects of our language knowledge and performance. More generally for society, they present an uncomfortable challenge for how we should handle evidence of genetically-based differences in fundamental language ability, should we find it.
\end{abstract}

\section{Introduction: Individual differences in linguistic ability}

It is indisputable that there is variation in individuals' ability to produce and use language effectively. We have all met the tongue-tied, people who can't remember jokes, pedants, punsters, those who can remember the numbers but not the letters on a car registration plate, loathers of poetry, talented wordsmiths, polyglots, those who struggle to grasp words on the tip of their tongue, diplomatic negotiators, and fluent gossipers. But where does that variation come from? Since so much of our linguistic behaviour is evidently determined by our environment - by our education and experience in particular - naturally we will first look there for explanations of difference between individuals. However, the role of genes is increasingly under examination, particularly now with focus on how genes and environment might interact. ${ }^{2}$ This new research offers linguists interesting challenges that extend beyond the domain of language description and modelling, to the heart of how we conceptualise our human linguistic heritage, and how we explain and address diversity. 


\subsection{The 'language faculty'}

One approach to understanding the nature of human language, most strongly championed by Noam Chomsky, ascribes to us all a uniform 'language faculty' (described further in section 3). Universal possession of this faculty means that all human languages are constructed according to its specifications, and this makes them all equally acquirable by children, who use the faculty to navigate a fast and reliable route through their input, to language-specific knowledge. On account of the language faculty, it is, in this approach, desirable to capture the essence of a language system as a logical description of its properties, and this is achieved using the linguist's intuitions about what constitutes a grammatical sentence. These intuitions are assumed to represent those of all native speakers (see later discussion of this point in section 7.1). In contrast, language as it is used in communication is considered a poor window on the underlying system, since various effects of production and performance intervene to present a partial and distorted impression of it. ${ }^{3}$

Compare how people engage with their personal computers. The language faculty is rather like the operating system, assumed to be the same for a given set of users, and to have a logical shape that can be described. However, people using it, while certainly exploiting aspects of its structure and bound overall to operate within what it permits, may actually use it in rather odd ways that reflect the experience they have had with it, and what they need to achieve. Not only might some aspects of the system not be reflected in their usage at all, but a simple underlying structure may appear very different, even countermanded, in usage, because intervening, less fundamental operations disguise it. Thus, the Chomskian argument is that the linguistic output of speakers is too channelled by circumstantial interventions to be an effective way of understanding the underlying system. The native speaker's intuitions, on the other hand, offer relatively direct access to it. Judgments about what sounds right, and how a given sentence can be grammatically re-expressed, reveal complex patterns of, and constraints on, configurations that do not always reflect maximum expediency in the communication of ideas. ${ }^{4}$

Theories of language that are based on emergent properties, on the other hand, ${ }^{5}$ would either deny, or downplay the importance of, an 'operating system' that is independent of what users do. A more appropriate analogy for them might be how a dance is learned. Someone starts doing some steps, and other dancers, through observation, begin to pick up the patterns. Over time, the novices become the experts, and others pick the dance up from them. There is a 'system' in the sense of a patterned dance, but it does not exist independently of the dancers, and it may change over time. That it always remains a dance - that there are consistent fundamental features such as rhythmic, repeated movements carried out standing up - can be attributed to physical and other characteristics shared by the dancers that are not themselves about dance (eg, being bipedal, having procedural memory), as well as a more general cognitive tendency to latch onto certain kinds of features as central, while others are peripheral. ${ }^{6}$

One can see, even from these two very imperfect analogies, that the role of cultural transmission, as opposed to genetic predisposition, is central to debates about 
language. The different positions can be characterised by imagining a generation that did not use the computer, or did not observe the dance: what would be left, what could re-emerge, and how similar would it be to what had previously existed?

\subsection{Engaging with similarity and variation}

In this paper I want to explore some of the assumptions and claims about the role of genes in defining the nature of human language. Much has been published on this topic already, and rather than rehearse existing arguments in depth, I shall often simply note their existence and move on. This is because I want to focus on some issues that have been less often brought out, including our social unease when it comes to challenging the entailment of the language faculty account, that all humans have an equal capacity for language at the fundamental level. ${ }^{7}$

In section 2, I contextualise the discussion by exploring perceptions of genes as agents of similarity and difference. Sections 3 and 4 deal with claims regarding the uniformity of our fundamental capacity for language, and why it is attractive to maintain this belief, even in the face of potential counter-evidence. In section 5, explanations for the origins of uniformity are considered, and in section 6 , I itemise some evidence of variation at the fundamental level. This leads to a testing, in section 7 , of the assumptions underpinning the interpretation of apparent evidence for genetically-determined uniformity in language, and the offering of an alternative explanation. Finally, in section 8 , I note the current interest in genetic variation in language performance, and consider the extent to which the role of environment in creating the appearance of genetic uniformity may have been under-estimated.

\section{Genes as agents of similarity and difference}

Genes make us the same as each other, and different from each other. At the species level, our genes make us human and other species non-human. At this level, genes explain why a child acquires language while the family dog does not, even though they may be spoken to equally and in not dissimilar ways. The essential humanness of language is not unduly diminished by evidence that apes can make quite a good job of language comprehension ${ }^{8}$ and that parrots display, in comprehension and speech, an impressive command of semantics; ${ }^{9}$ for there is no real evidence as yet that nonhuman species have grasped the key features of human language structure (see section $3) .{ }^{10}$

At the same time, we see our genes as part of the reason why we are different from even our siblings (unless we have an identical twin, in which case differences must be explained another way). Individual characteristics can be the result of a random mutation or copying error in our DNA, but most of them are inherited and have only the appearance of uniqueness, because no one else in the family happens to have expressed the trait. Between the two extremes of shared human-ness and individuality, we also recognise how certain genes, particularly but not only those responsible for visible traits, make us like our family, but different from those outside the family. Extending upwards, we acknowledge that our genes give us visible physical characteristics that make us look more similar to people in some populations in the 
world than others. Thus, our perception of the role of the gene contributes to how we construct our personal and social identity as a combination of differences from, and similarities with, others.

Where in this picture, then, do we locate differences in people's language ability? Are they reflections of those genes that make us individual - perhaps genes directly determining some aspect of our capacity for language - or are they a superficial, environmentally-determined layer atop fundamental uniformity for language ability? Or both? Generally, there has been a tendency to acknowledge that differences in aspects of our language ability can have a genetic basis, but to view the genetic component as non-linguistic, with linguistic consequences. For instance, poor memory or low concentration could affect the ability fully to benefit from opportunities for learning the finer skills of language presented experientially. Such explanations seem more comfortable for us than proposing that particular genes directly determine why our vocabulary size is different from someone else's, or why we are particularly good, or bad, at learning other languages. Research evidence so far appears to concur. Although a single-point mutation of the FOXP2 gene has been associated with language deficits, the gene's role seems to be in regulating brain development, with knock-on effects for language, rather than directly supporting articulation or grammar. $^{11}$

It may be feasible to explain everything about language in terms of the interaction of environmental influences and genetically-endowed abilities that are not of themselves specifically linguistic. What is uniform about how we engage with linguistic structure would, then, be a natural consequence of how these factors interact. However, proponents of the language faculty believe otherwise - the faculty is construed as a uniform, language-specific genetic inheritance.

\section{Structural arguments for language uniformity}

Over some 50 years, Noam Chomsky has maintained that humans possess a "language organ" whose "basic character is an expression of the genes."12 According to Chomsky, our basic genetic endowment determines an "initial state of the language faculty", "a 'language acquisition device' that takes experience as 'input' and gives the language as an 'output' ... that is internally represented in the mind/brain." "The language faculty is logically necessary, Chomsky claims, to explain how children acquire their first language with such extraordinary speed and consistency, irrespective of the quantity and quality of the input and, in particular, how they are able to infer certain grammatical patterns on the basis of only negative evidence. The faculty ensures that children know what to look for in the input, in order to make structural sense of it. ${ }^{14}$ In recent accounts just two properties lie at the heart of this universal knowledge of language grammar: structure dependence and recursivity. After briefly reviewing the nature of each, we shall also consider one of the properties claimed to be consequential on them, Subjacency. 


\subsection{Structure dependence}

In structure dependence, small units of language combine into larger units, and units maintain their underlying integrity if the sentence is reformulated. To briefly exemplify, turning the statement in (1) into the question in (2) entails the recognition that the 'was' that moves to the start of the question is the second one in (1), not the first one. The clause 'that was seen in the River Thames' is a unit embedded in another unit, 'The whale was a juvenile'. The question formation involves this outer clause, not the embedded one, so that it is the verb in the outer clause that is fronted, not its identical counterpart in the embedded clause.

1) The whale that was seen in the River Thames was a juvenile.

2) Was the whale that was seen in the River Thames a juvenile?

Chomsky argues that if children did not come to language acquisition already knowing the principle of structure dependence, they could all too easily infer, from simpler examples such as (3) that the rule was 'move the first verb to the front', an adequate way to generate (4), but also leading to the creation of the ungrammatical (5). ${ }^{15}$ (The asterisk on (5) indicates that the sentence is classified as ungrammatical).

3) The whale was a juvenile.

4) Was the whale a juvenile?

5) *Was the whale that seen in the River Thames was a juvenile?

The ubiquity of structure dependence in language, and its possible non-linguistic precursors in our species, as indicated by counterparts in animal cognition, ${ }^{16}$ mean it is hardly contentious to suppose that humans possess some sort of innate disposition towards it. However, many, including Newmeyer, still see it as specific, in its instantiation, to the language faculty: "The structure dependence of grammatical rules might well have its evolutionary antecedence in some general human (or, more likely, biological) preference for structural solutions to complex problems. But structure dependence in grammar is a highly specific adaptation of this general preference."17

\subsection{Recursivity}

Recursivity is the single feature identified by Hauser, Chomsky and Fitch as making human language unique. ${ }^{18}$ Recursivity in language means that the output of one grammatical operation can act as the input for another. The effect is that there is no logical bar on the complexity of sentences. It is, for instance, grammatical to embed one clause inside another, then another inside that, another inside that, and so on (610). ${ }^{19}$

6) The mechanic tells fortunes.

7) I know the mechanic tells fortunes.

8) I know the mechanic the tailor saw yesterday tells fortunes.

9) I know the mechanic the tailor who makes those suits saw yesterday tells fortunes.

10) I know the mechanic the tailor who makes those suits you were thinking of buying saw yesterday tells fortunes. 


\subsection{Subjacency: a consequential property}

In Chomsky's models until the mid-1990s, certain additional properties of language were considered universals in their own right. One of them was Subjacency.

Subjacency constrains grammatical relations arising from embedding. When one clause is embedded inside another, grammatical dependencies can arise across them. An item in one clause may cross-refer to an item in another; an item in one clause may be deleted because it also exists in another, setting up a dependency between the explicit item and the gap where the deleted item was; or an item may be 'moved' into another clause in order to fulfil a particular function, as in English when wh-questions are created. Subjacency prevents the linked items - in the case of a wh-question, the moved $w h$-word and its original location (or trace) - becoming impossible to track, by constraining the amount and type of structural material that may intervene. The effect is to allow (12) but not (13) as grammatical developments of (11), even though (13) is simply a $w h$-fronted version of (14).

11) Elsie bought a coat.

12) What do you believe (that) Elsie bought?

13) *What do you believe the claim that Elsie bought?

14) You believe the claim that Elsie bought what?

Chomsky's Minimalist Program simplified the notion of Universal Grammar, by making principles like Subjacency a logical consequence of the two core featuresstructure dependence and recursivity_plus language-specific rules. ${ }^{20}$ Thus, "the learning child ... minimally needs a notion of hierarchical structure plus an understanding of transformations and constraints on them." ${ }^{21}$ Adherence to Subjacency is ensured if the child knows that the progressive stages by which a 'transformed' sentence such as a wh-question is constructed must occur sequentially, in "'successive cyclic' movements, each of which cross a minimal unit of structure.",22 Violations of Subjacency occur when one or more of the individual cycles cannot be completed, on account of an item occupying a slot that must be empty when that cycle takes place. In section 6 we shall consider the claim that Subjacency cannot be construed as 'universal' since it does not manifest in all languages.

\section{Social arguments for uniformity}

Although syntactic models of language knowledge and sociolinguistic descriptions of language behaviour have generally had little to say to each other, they have common socio-political foundations. Sociolinguistic theory has maintained over many years that varieties spoken by uneducated groups, typically viewed by the establishment as aberrant consequences of ignorance, are in fact no less complex or expressively rich than the standard variety. ${ }^{23}$ These observations are consistent with the egalitarian Chomskian position: we all start with the same genetically endowed language faculty and use it to treat our input. Since our language faculty obliges us to shape our input data in particular ways, it follows that all output will be of the same fundamental complexity. Therefore, while socially imbued contrasts between languages and varieties cannot be denied, they are only that. Change the social conditions, and the 
variety viewed as most 'ignorant' could become the one considered most correct and desirable.

It is clearly socially problematic to suggest that one speaker group is in any way fundamentally disadvantaged for language relative to another. ${ }^{24}$ Socially induced differences (education provision, access to books, cultural priorities) can be put right through social policies. It would be different indeed to suggest, for instance, that members of a particular group had encoded in their genes a different type of language faculty, that predisposed them to lesser, or greater, capability for language. As with intelligence, ${ }^{25}$ language ability is an invisible and contingent trait: it is not known unless it is measured, and it is defined according to particular social values. Such traits are particularly socially sensitive because of the ease with which their presence can be inappropriately inferred by association with a proxy, visible trait such as skin colour, age, gender or disability. The association of invisible traits with visible ones is invidious because unless both are equally ubiquitous (and anything socially interpreted will tend not to be) the one is not a reliable index of the other. To put it crudely, it is socially unacceptable - and for good reason - to look at someone's appearance and infer thereby that they will be less intelligent or a less able language user than someone else.

The uniformitarian perspective on language arose in response to racialist attitudes, whereby it was presumed that the 'noble savage' possessed a lesser (or occasionally greater) capacity for language than the European, and that different races could be located at different points on a directional evolutionary continuum. ${ }^{26}$ It is anathema to modern western society that anything construed as desirable should be entirely unattainable, and thus much more comfortable to downplay any notion of fixed ceilings of achievement, whether associated with random individuals, family groups, classes or, most undesirably of all, 'races'. 27

Yet genetics research is increasingly likely to demand answers to difficult questions. In the account above I have focussed on the least desirable scenario, whereby some genetically-determined variation creates 'inequality'. That is, where some populations are viewed as better at language, in some sense, than others, in a way that parallels the claims for systematic differences in IQ levels. However, not all differences entail inequality, and one line of recent research indicates the scope for challenging the notion of uniformity without an associated social stigma. Research by Dediu and Ladd $^{28}$ suggests that a particular pattern of genetic variation (derived haplogroups of two genes) explains the distribution of tone languages around the world. Tone languages use patterns of pitch change to differentiate meanings. Dediu and Ladd propose that " $[\mathrm{t}]$ hose areas of the world where the new alleles are relatively rare also tend to be the areas where tone languages are common," ${ }^{29}$ and that the relationship is causal - "the genetic structure of a population can exert an influence on the language(s) spoken by that population." 30 They hypothesise that the genetic effects on brain structure determine how tone is handled during the process of language acquisition, with an impact, in heavily affected populations, on the culturally transmitted linguistic code. That is, languages spoken by populations in which many individuals have some difficulty in processing tone will tend to lose their tonal 
features. They are careful to note that "there is no evidence that tone itself confers any advantage or disadvantage on speakers," ${ }^{31}$ so this particular effect should be socially neutral. However, we must not forget that society often interprets variation judgmentally, and where systematic difference is once found, prejudice may follow.

\section{Explanations of uniformity}

Chomsky's claim that all humans possess the same fundamental language knowledge draws us inexorably to the question of when and how that knowledge arose, and how it is that humans today still all have it. The most plausible answer to the first part of the question is that it arose in the small sub-population of humans whose descendents we all are, and that possessing it gave the ancestral sub-population a distinct survival advantage over contemporaries without it. In order to avoid the complications of polygenesis, ${ }^{32}$ we assume the language faculty arose once only, some time before modern man dispersed out of Africa around 100,000 years ago. ${ }^{33}$ As to explaining its uniformly reliable persistence, there are at least three options. One is that selection pressures ensure the failure of anyone without the language faculty to survive and reproduce. Another is that the language faculty, while less than crucial for survival on its own, is tied into other basic human functions without which an individual could not survive and reproduce. A third is that the genetic basis of the language faculty is highly conserved, that is, remarkably resilient to mutation. ${ }^{34}$

It is for others to weigh the plausibility of these and other options. It need only be noted here that such evolutionary accounts are predicated on the assumption of uniformity today, so evidence challenging the extent of that uniformity (see section 6) potentially impacts on our understanding of what evolved and how. ${ }^{35}$

\section{Evidence for variation}

What sort of variation in language knowledge or performance would directly challenge the claim that we have a genetically-endowed language faculty? Although, as we shall see in section 8 , there is place for examining the relative roles of genes and environment in the variation found across a wide range of aspects of language knowledge and performance, that agenda arises separately, and somewhat independently, of the claim for a language faculty. For the present, therefore, the question is whether variation can be adduced in relation to the language knowledge that the innateness accounts have construed as immutable. As we saw in section 3, this knowledge relates to two core features of language, structure dependence and recursivity, and a range of consequential features, including Subjacency, previously identified as central to Universal Grammar.

Before Subjacency and other similar principles were 'down-graded' it was reasonable to argue that if one could find a language without Subjacency, one had found evidence that the theory of Universal Grammar was invalid. However, Newmeyer ${ }^{36}$ promotes the weaker version of UG theory that the Minimalist Program makes possible. It is unproblematic to find languages without Subjacency, so long as this is only because there is no scope for it to apply (eg, because the language does not use sufficiently 
complex embedding). However, it is vital for the theory that when the language develops the additional clausal complexity that provides the forum for Subjacency to apply, then it will apply.

The weak Universal Grammar hypothesis challenges its opponents to offer a more compelling kind of evidence than simply the absence of Subjacency in languages without multiple embedding, eg:

i) Evidence of the grammatical acceptability of Subjacency violations in languages that do have adequate levels of embedding;

ii) Evidence of languages failing to apply recursion, even when expressing appropriate semantic dependencies;

iii) Evidence that individuals given examples of complex sentences cannot reliably understand them;

iv) Evidence of languages failing reliably to demonstrate structure dependence.

There is not, to my knowledge, any instantiation of (iv), though it must be borne in mind that the assumption of structure dependence is so basic a notion to us, that it would be difficult to describe a new language without doggedly pursuing the expectation of it, even if it was not there. ${ }^{37}$ Meanwhile, Wray ${ }^{38}$ provides (incidentally) a means of explaining away any examples that appear at odds with structure dependence, by proposing that communication is not always reliant on rulebound forms. Formulaic expressions can become and remain irregular by being processed as single lexical entries.

The other three proposed types of evidence are apparently attested. Regarding (i), Culicover notes that "there are languages such as Italian, Swedish and Icelandic in which systematic violations of Subjacency are possible, in the sense that sentences which would be judged ungrammatical in English are judged grammatical in these languages. There is evidence that it does not even hold uniformly for English." 39

In relation to (ii), Everett ${ }^{40}$ has claimed that Pirahã, a language spoken in the Brazilian Amazon, does not display recursion - it has no embedding. Less extreme claims have been made regarding other languages. Mithun suggests that "[1]anguages and speakers vary considerably in the exploitation of this syntactic device" ${ }^{41}$ and, like Ong, ${ }^{42}$ she sees subordination as a feature of writing rather than speech. ${ }^{43}$ Kalmár $^{44}$ reports a marked increase in grammatical subordination in Inuktitut after decontextualised writing, and translation from English, became more common. In the weaker version of the Universal Grammar hypothesis, the absence of embedding is inconsequential if, on account of having no written tradition, for instance, the relevant semantic dependencies are not expressed at all. But Everett proposes that Pirahã does express the meanings that other languages achieve through embedding, and this constitutes one part of his claim that Pirahã stands outside the scope of predicted 'possible' languages.

Evidence of variation in people's capacity to understand complex embedded sentences (iii) has been offered by Chipere. ${ }^{45}$ His experimental stimuli were sentences like (15), 
for which he solicited both direct repetitions and answers to comprehension questions (eg, What does the doctor know? and What surprises Tom?).

15) The doctor knows that the fact that taking good care of himself is essential surprises Tom.

He found non-graduate native speakers less able than native and non-native speaker graduates to take into account the various parts of the structure when responding to comprehension questions. Since the non-native speaker graduates actually gave the most accurate responses to some questions, Chipere suggests that explicit instruction in the grammar of English (of which the non-native graduates would have experienced most and the non-graduate native speakers least) is of assistance in understanding complex sentences.

He also found that individuals unable to remember or understand the stimuli responded well to training, explaining his results by means of Ericsson \& Kintsch's proposal that "in skilled activities, acquired memory skills allow [the] products [of interim operations] to be stored in long-term memory and kept directly accessible by means of retrieval cues in short-term memory." 46 Chipere suggests that training in how to understand complex sentences supports the development of a rule-based strategy for unpacking them, without which it is more natural to interpret them by analogy, using "syntactic formulae, ... impose[d] top-down on the input". ${ }^{47}$ Possible implications of Chipere's proposal are considered in section 8 .

\section{Causes and effects of variation}

\subsection{Cultural enhancements of language}

If one believes that all languages are essentially equal in complexity, all the natural product of a species-wide language capacity, it is not unreasonable to examine only a small number of languages in order to identify the features of that capacity. However, for as long as these beliefs are only beliefs, it is obviously necessary to ensure that there is no bias in the sample, lest one attribute universality to some feature that is a secondary accretion peculiar to the sampled languages. Grace ${ }^{48}$ outlines dangers inherent in a culture-centric approach to language description. English, the language most often drawn upon for modern linguistic analysis, is in many respects an artificial language. It has a long history of literary development and of standardisation. While it remains 'natural' in the sense that native speakers acquire it, the version they acquire is frequently treated as culturally inadequate, so that additional training, through education, is required to master the niceties of specific varieties elevated as 'correct'. Since the features of this 'correctness' have accreted over time-mostly as expressions of preferences imposed by intellectual adults ${ }^{49}$ and often emulating patterns in Latin and Greek - there is no reason why the standard forms of English, locked into writing, though then extrapolated back as an educated spoken code, should reflect all and only natural patterns. The kinds of sentences at the heart of Chomskian accounts of complex grammar might therefore be 'unnatural'. 
In an application of Grace's ideas to the question of language evolution, Wray \& Grace $^{50}$ offer a model of how cultural demands, particularly the need to talk to 'outsiders', augment a less ambitious default version of language structure in the direction of greater explicitness and regularity. One outcome might be a greater use of embedding for encoding complex meaning relationships in a retrievable way. Wray \& Grace propose that for most of human evolution, languages have not been under the cultural pressure that augments their form in these directions.

\subsection{Genetic variation over time}

The evolutionary origin of language also offers another potential explanation for variation between languages at the fundamental level. Let us suppose that a dedicated language faculty did arise in our species some time around or after 200,000 years ago. Our earliest modern ancestors, let us imagine, understood the principles of structure dependence and recursion. Let us further suppose that they understood structural relations in multiply embedded sentences after the movement of constituents - even though their spoken language(s) never provided a context in which to exercise that knowledge.

Although this provides a uniform starting point for our species, under what circumstances would that uniformity remain? Two hundred thousand years is a very long time for a trait to be maintained with $100 \%$ reliability across the human population, when it is not in use, and when no disadvantage ensues from its absence. ${ }^{51}$ Why, over the many millennia during which — if Wray \& Grace are right — embedding was barely in use, might not some humans emerge, who by virtue of slightly different innate language knowledge, or on account of some difference in how they approach information processing and storage, find embedded structures more difficult to compute? At the time, no one would notice, whether it were a trait in random individuals across all populations, or one passed down in family lines. In theory, it could even come to characterise one gender more than the other, or a particular coherent population - we are back on socially sensitive ground.

My aim is not particularly to suggest that the universality of an original language faculty actually has been undermined by silent genetic variation, so much as to indicate that we need to explain why it could not have been. In actual fact, were we to become satisfied that a feature of language such as recursion was not equally represented in the innate knowledge of all individuals, we should probably not wish to hypothesise the undoing of something originally ubiquitous at all, unless there was no other way to explain the origins of its vestiges in the species. Even so, the idea that we have innate linguistic knowledge the detail of which has diverged in the course of evolution is too important to set aside, and it raises interesting issues for consideration, as explored in the final section.

\subsection{Less than black and white}

A few years ago people talked simplistically of a 'language gene', and that made it easy to conceptualise all humans as equally linguistically endowed. But the accepted view now is that our capacity for language is determined by many genes, many or all

Genomics, Society and Policy, Vol.4, No.1 (2008) ISSN: 1746-5354

(C) ESRC Genomics Network. 
of which might exist in variant forms. Whether defining language as a 'complex trait' obviates the possibility that there lies at their heart some special, invariant faculty dedicated to language is a topic of continuing debate.

As for perceptions of the role of the environment, they too have become more complex. Although it remains likely that much of the variation in language and languages is culturally-determined and maintained, it is now increasingly recognised that genes and environment interact. For example, in epigenetics the expression of the gene is determined by an environmental trigger. ${ }^{52}$ Nettle $^{53}$ tentatively suggests another kind of gene-environment interaction in relation to Dediu and Ladd's findings for tone languages, described earlier. Where they propose that a particular genetic expression may have influenced the properties of a pattern in the languages spoken by the affected people, Nettle additionally proposes that, in return, the language features could have led to positive selection for that gene expression in subsequent generations. $^{54}$

The more complex the genetic and environmental factors determining language are seen to be, the harder it is to be sure on what basis we can safely judge a feature of language to be truly invariant across all normal humans. Most research discusses whether or not the phenomenon of language can be explained without recourse to a universal language faculty, but in this paper I have focussed on two different questions - whether the faculty, if it did exist, could have variant forms, and whether, if it did, we would be able to tell.

Specifically, I have explored the possibility that our cultural engagement with language influences our linguistic knowledge at the most fundamental level, and I have considered whether our evolutionary development could have supported a bifurcation (or more) in people's innate knowledge about language, as the result of genetic variation. Were both true, it could mean that what one person did through innate knowledge, another could learn to do. Chipere's ${ }^{55}$ work offers one candidate type of knowledge - the processing of complex embedded structures using long term memory. ${ }^{56}$ Inherited predispositions to handle complex embedded structures without, versus only with, training would constitute a very subtle distinction of no consequence, until cultural practices arose that prized the ability to encode and decode complex language, while the associated educational system was less than vigilant about teaching that ability to those not immediately adept. Such circumstances could play a role in creating and sustaining differences in social and material attainment. Since the skill was learnable, bootstrapping would be entirely feasible, but effort would be entailed if one were to match the natural abilities of those with the innate disposition.

Irrespective of the plausibility of this particular scenario, variation between individuals in relation to what we term 'language aptitude' or 'flair for language' does exist and may not be easily explained in terms of environment alone. For this reason there is an urgent need for research into the genetic basis for the many aspects of variation in language knowledge and aptitude - as now being undertaken for Specific Language Impairment, ${ }^{57}$ and through twin studies. ${ }^{58,59}$ Twin studies can help separate 
out the genetic contribution to variation from that partly or entirely due to environment. Evidence suggests, however, that not only postnatal but also perinatal environmental factors play a role in how language develops, ${ }^{60}$ a fact that complicates assumptions about genetically identical input being expressed identically in different individuals even in the early years of life.

Establishing the role of genes in determining our language abilities is only one part of the challenge, however. The other is learning to cope with all of the possible outcomes of such research. A mature society needs a means of dealing with the discovery of genetically-based differences in capabilities that, on strongly defensible cultural grounds, we would rather believe were fundamentally invariant.

\section{Acknowledgements}

The Cardiff symposium 'What is special about the gene?' provided the impetus for developing many of the ideas in this paper. I am grateful to Stephen Pattison and Andrew Edgar for their invitation to participate. The paper has benefited from helpful comments and advice from Alison Sealey, Naomi Wray, and two anonymous referees, and from discussions with Tess Fitzpatrick, George Grace, Eugène Mollet and Mike Wallace, to all of whom I express my thanks.

\footnotetext{
${ }^{1}$ Centre for Language and Communication Research, School of English, Communication and Philosophy, Cardiff University, UK wraya@cf.ac.uk

${ }^{2}$ For some discussion, see D. Nettle. Language and genes: a new perspective on the origins of cultural diversity. Proceedings of the National Academy of Sciences 2007; 104 (26): 10755-10756.

3 "Linguistic theory is concerned primarily with an ideal speaker-listener, in a completely homogeneous speech-community, who knows the language perfectly and is unaffected by such grammatically irrelevant conditions as memory limitations, distractions, shifts of attention or interest, and errors (random or characteristic) in applying his knowledge of the language in actual performance". N. Chomsky. 1965. Aspects of the Theory of Syntax. Cambridge, MA: MIT Press, p.3.

${ }^{4}$ Examples of constraints that do not seem to translate into use include the one that outlaws *The asleep girl as a re-expression of The girl is asleep (compare The expensive car as a re-expression of The car is expensive). Constructions that are attested in usage but are outlawed by intuition include the one underlying What's the one episode that you wrote, that when you saw it, it just blew you away? (interview with Ronald D. Moore, writer of Roswell, www.scifi.com/sfw/issue234/interview.htlm, accessed 27.01.08). A striking example of a structure that Generative grammars predict but which is very rarely attested is gapping, eg, I ate fish, Bill rice and Harry roast beef, which Tao \& Meyer (2006) describe as "one of the most extensively studied syntactic constructions in English" (p.129) but one that is very rarely found in corpus data. In the ICE-GB corpus ( 1 million words) they found 17,629 clauses that were structured appropriately to permit gapping, but only $120(0.7 \%)$ that actually had it. ${ }^{5}$ eg, Construction Grammar. See for instance, A.E. Goldberg. 2006. Constructions at Work, Oxford: Oxford University Press, chapter 1.

${ }^{6}$ Chomskian models do not exclude a role for general cognitive influences, but do view them as complementing the dedicated language faculty.

${ }^{7}$ The assumption of uniformity in humans leads to assumptions about uniformity in languages. It is claims like "we find the same basic structural properties in every human language", S.R. Anderson. 2004. Doctor Dolittle's Delusion. New Haven, CT: Yale University Press, p.199 that are increasingly being challenged (see later). The tendency for an idea to become commonly accepted without adequate evidence is exemplified by Pullum and Scholz in relation to another common claim in linguistics, that
} 
languages have infinite expressional capacity. G. Pullum and B. Scholz. 2008. Language and the infinitude claim. http://ling.ed.ac.uk/ gpullum/bcscholz/Infinitude.pdf, accessed 28.01.08.

${ }^{8}$ eg, K.E. Brakke and E.S. Savage-Rumbaugh. The development of language skills in bonobo and chimpanzee - I: comprehension. Language and Communication 1995; 15 (2): 121-148.

${ }^{9}$ eg, I.M. Pepperberg.1999. The Alex Studies. Cambridge, MA. Harvard University Press.

10 Anderson, op. cit. note 7.

${ }^{11}$ eg, F. Vargha-Khadem et al. FOXP2 and the neuroanatomy of speech and language. Nature Reviews Neuroscience 2005; 6: 131-137. Language deficits in the KE family seem to include articulatory problems and difficulty applying the agreement rules on verbs and nouns. They have been linked to a single base substitution in FOXP2, on Chromosome 7.

${ }^{12}$ N. Chomsky. 2000. New horizons in the study of language and mind. Cambridge: Cambridge

University Press, p.4

${ }^{13}$ Chomsky, op. cit. note 12 .

${ }^{14}$ As part of his energetic argument against the notion of a genetically-determined language faculty, Geoffrey Sampson (The 'Language Instinct' Debate, London: Continuum, 2005) counters each of Chomsky's key claims in turn, arguing that they are predicated on invalid assumptions about the nature of the input presented to children and the bases on which it could result in the kind of output they produce. Taking a different approach to the challenge, G. Pullum \& B. Scholz, Empirical assessment of stimulus poverty arguments. Linguistic Review 2002; 19 (1-2): 9-50, identify the evidential requirements for arguing for or against innate knowledge.

${ }^{15}$ N. Chomsky. 1976. Reflections on Language, London: Fontana/Collins, p.33ff.

${ }^{16}$ J.R. Hurford, 2007. The origins of meaning. Oxford, Oxford University Press.

${ }^{17}$ F. Newmeyer. 2005. Possible and probable languages. Oxford: Oxford University Press, p. 11-12.

${ }^{18}$ M. Hauser, N. Chomsky and W.T. Fitch. The faculty of language: what is it, who has it, and how did it evolve? Science 2002; 298, 22/11/02, 1569-1579.

${ }^{19}$ However, see Pullum and Scholz 2008, op. cit. note 7 for reasons why this capacity for infinite embedding has been generally overstated.

${ }^{20}$ Newmeyer, op. cit. note 17, chapter 3.

${ }^{21}$ W. Hinzen. 2006. Mind Design and Minimal Syntax. Oxford: Oxford University Press, p.196.

${ }^{22}$ Hinzen, op. cit. note 21, p.198.

${ }^{23}$ eg, W. Labov. The logic of non-standard English. In J. Alatis ed. Georgetown Monographs on Languages and Linguistics 1969; 22, 1-44.

${ }^{24}$ The focus here is on the 'normal' population (though normality is, of course, a social construct). See a later note for comments on abnormal language.

${ }^{25}$ See, for instance, the recent furore over claims by James Watson of differences in intelligence between black, white and Asian people: Times Online. 2007. Black people 'less intelligent', scientist claims. http://www.timesonline.co.uk/tol/news/uk/article2677098.ece

${ }^{26}$ G. Radick. 2008, The Simian tongue: the Long Debate about Animal Language. Chicago: University of Chicago Press, chapter 5.

${ }^{27}$ The concept of 'race' is generally recognised to be a social construct that does not map effectively onto the biological evidence. See, for example, L. Lieberman and F.L.C. Jackson. Race and three models of human origin. American Anthropologist 1995; 97 (2): 231-242.

${ }^{28}$ D. Dediu and D. R. Ladd. Linguistic tone is related to the population frequency of the adaptive haplogroups of two brain size genes, APSM and Microcephalin. Proceedings of the National Academy of Sciences 2007; 104 (26), 10944-10949.

${ }^{29}$ Dediu and Ladd, op. cit. note 28, p.10945.

${ }^{30}$ Dediu and Ladd, op. cit. note 28, p. 10946.

${ }^{31}$ Dediu and Ladd, op. cit. note 28, p. 10946.

${ }^{32}$ I use the term polygenesis as linguists do, to refer to the independent emergence of language more than once in the human species. It contrasts with monogenesis, a single emergence event, often assumed to entail both the cognitive capability for language processing and the first linguistic code, from which all subsequent languages have developed (though there is certainly scope to account for these events separately). Polygenesis has a different meaning in genetics, which is not intended here. ${ }^{33}$ Estimates tend to assume the emergence of modern man, with language, 200,000 to 150,000 years ago, in Africa. There are other hypotheses too, however, including a much later date coinciding with 
the first cultural evidence of language (eg, religious rituals, cave art). But language emergence after the dispersal from Africa obviates a monogenetic origin for language, and polygenesis naturally weakens the claim for uniformity across all languages.

${ }^{34}$ Vargha-Khadem et al. op. cit. note 11, p. 137.

${ }^{35}$ Of course, not all linguists by any means believe that there is a 'language faculty' as such at all, and all linguists accept that the language package as a whole (including speech, naming, remembering, assigning thematic roles to participants in clauses, etc.) has entailed the presumably independently motivated evolution of many different abilities.

${ }^{36}$ eg, op. cit. note 17. Also F. Newmeyer. 2002. Uniformitarian assumptions and language evolution research. In A. Wray (ed.) The Transition to Language. Oxford: Oxford University Press, 359-375.

${ }^{37}$ Compare Boas' advice to the anthropologist, to "divest himself entirely of opinions and emotions based on the peculiar social environment into which he is born”. F. Boas. The Mind of Primitive Man. Journal of American Folk-Lore 1901; 14 (52), 1-11.

${ }^{38}$ A. Wray. 2002. Formulaic Language and the Lexicon. Cambridge: Cambridge University Press.

${ }^{39}$ P. Culicover. 1996. Adaptive Learning and Concrete Minimalism. In C. Koster and F. Wijnen, eds, Proceedings of the Groningen Assembly on Language Acquisition. Groningen Assembly on Language Acquisition (GALA 1995), Center for Language and Cognition, Groningen, 165-174. Available at http://www.ling.ohio-state.edu/ culicove/Publications/GALA.pdf, last accessed 28.01.08

${ }^{40}$ D. Everett. Cultural constraints on grammar and cognition in Pirahã. Current Anthropology 2005; 46, 4: 621-646.

${ }^{41}$ M. Mithun. How to avoid subordination. In Proceedings of the Tenth Annual Meeting of the Berkeley Linguistics Society 1984; 493-523, p. 509

${ }^{42}$ W.J. Ong. 1982. Orality and Literacy: The Technologizing of the Word. Methuen, London.

${ }^{43}$ Some culturally developed types of spoken language, such as oral epics, may also display structural complexity. Oral literature is characterised by repetition, a creative mix of familiar formulae and new material, and opportunities for both speaker rehearsal and multiple hearings; see discussion in A. Wray. forthcoming. Formulaic Language: Pushing the Boundaries. Oxford: Oxford University Press.

${ }^{44}$ I. Kalmár. 1985. Are there really no primitive languages? In D.R. Olson, N. Torrance and A. Hildyard eds. Literacy, Language and Learning. Cambridge: Cambridge University Press, 148-166. ${ }^{45}$ N. Chipere. 2003. Understanding complex sentences. Basingstoke: Palgrave.

${ }^{46}$ K.A. Ericsson and W. Kintsch. 1995. Long term memory. Psychological Review 102, 2, 211-245, p.211.

${ }^{47}$ Chipere, op. cit. note 45, p. 180.

${ }^{48}$ G.W. Grace Collateral damage from linguistics? 3: The role of culture-centrism. Ethnolinguistic Notes 2002; 4 (23) http://www2.hawaii.edu/ grace/elniv23.html, accessed 28.01.08.

${ }^{49}$ The difference between how adults approach the identification of language patterns, compared with children, is explored at length in Wray op. cit. note 38.

${ }^{50}$ A. Wray and G.W. Grace. The consequences of talking to strangers: Evolutionary corollaries of socio-cultural influences on linguistic form. Lingua 2007; 117, 543-578.

${ }^{51}$ It is, of course, possible that the trait, though not used for language, was vital for something else, such as organising thought, or planning actions. This argument, however, entails that the trait is not part of a dedicated language faculty.

52 eg, M.F. Fraga et al. Epigenetic differences arise during the lifetime of monozygotic twins.

Proceedings of the National Academy of Sciences 2005; 102 (30): 10604-10609.

${ }^{53}$ Fraga, op. cit. note 52.

54 This process is known as the Baldwin effect.

${ }^{55}$ Chipere, op. cit. note 45.

${ }^{56}$ Dediu and Ladd, op. cit. note 28, offer another. As with the present account, they propose that the variation would not be sufficient to disadvantage an individual. Their account explores the effect on languages of many individuals in a population exhibiting a particular trait, something that could logically extend to the present scenario too.

${ }^{57}$ Abnormalities in language can take many forms, and they are generally attributed to impairments in one or more component of the complex package that supports the hypothesised language faculty (eg, auditory processing, memory, planning, production processing, social interaction, reading). For an overview, see G. Barnby and A. Monaco. 2007. Speech and language disorders. In A. Wright and N. 
Hastie, eds. Genes and Common Diseases: Genetics in Modern Medicine. Cambridge: Cambridge University Press, pp. 469-487. So far there has been no convincing evidence of impairment to just a 'language faculty' in the narrow sense defined in this paper, though it is far from clear what one should look for in identifying an affected person.

${ }^{58}$ For a comprehensive review of published studies, see K. Stromswold. The heritability of language: a review and meta-analysis of twin, adoption, and linkage studies. Language 2001; 77, 4, 647-723.

${ }^{59}$ My own current project (April 2007- Sept 2008), funded by the UK Arts and Humanities Research Council and in collaboration with the Twin Study at the Queensland Institute of Medical Research, is applying a wide range of language profiling techniques to essays written by identical and non-identical twins in a state-wide school examination.

${ }^{60} \mathrm{~K}$. Stromswold. Why aren't identical twins linguistically identical? Genetic, prenatal and postnatal factors. Cognition 2006; 101, 333-384.

Genomics, Society and Policy, Vol.4, No.1 (2008) ISSN: 1746-5354

(c) ESRC Genomics Network. 